\title{
ABT-737 potentiates cisplatin-induced apoptosis in human osteosarcoma cells via the mitochondrial apoptotic pathway
}

\author{
FENGTIAN ZHANG ${ }^{*}$, XIAOLONG YU*, XUQIANG LIU, TONGHUA ZHOU, \\ TAO NIE, MING CHENG, HUCHENG LIU, MIN DAI and BIN ZHANG
}

\begin{abstract}
Department of Orthopedics, The First Affiliated Hospital of Nanchang University, Artificial Joints Engineering and Technology Research Center of Jiangxi Province, Nanchang, Jiangxi 330006, P.R. China
\end{abstract}

Received March 10, 2017; Accepted August 7, 2017

DOI: $10.3892 /$ or.2017.5909

\begin{abstract}
ABT-737 is a $\mathrm{BH}-3$ mimetic that inhibits Bcl-2 and induces apoptosis of cancer cells, which has potential for anticancer therapies. Studies have shown that Bcl-2 expression in human osteosarcoma (OS) cells plays a significant role in tumor progression; however, its effects on OS cell apoptosis are still unknown. Therefore, we examined whether ABT-737 was effective in eliminating human U-2OS cells, either alone or in combination with the chemotherapy drug cisplatin [cis-diamminedichloroplatinum (II); DDP]. Furthermore, we studied the molecular mechanisms of ABT-737 in combination with DDP to induce apoptosis. To analyze the role of ABT-737 and/or DDP on osteosarcoma progression, CCK-8 viability assay, flow cytometry, Hoechst 33258 staining, and western blots were performed. Combined use of ABT-737 and DDP synergistically suppressed cell viability and induced apoptosis in human U-2OS cells when compared with either compound treated alone at low doses. We found that the combination of ABT-737 and DDP upregulated the expression of the proapoptotic protein Bax and downregulated the expression of the pro-survival protein Bcl-2, resulting in a change in the $\mathrm{Bax} / \mathrm{Bcl}-2$ ratio, release of cytochrome $c$, and activation of the mitochondrial apoptotic pathway, which resulted in caspase-9 and caspase- 3 activation and PARP cleavage. Our results demonstrated that ABT-737 alone has a nominal influence on human U-2OS cells when treated within the clinically administered range, but when combined with DDP, it can inhibit the
\end{abstract}

Correspondence to: Dr Bin Zhang or Dr Min Dai, Department of Orthopedics, The First Affiliated Hospital of Nanchang University, Artificial Joints Engineering and Technology Research Center of Jiangxi Province, 17 Yong Wai Zheng Street, Nanchang, Jiangxi330006, P.R. China

E-mail: z5802100@126.com

E-mail: 1135547344@qq.com

*Contributed equally

Key words: cisplatin, ABT-737, human osteosarcoma, anticancer activity, apoptosis, mitochondrial pathway proliferation of human U-2OS cells by inducing apoptosis via the mitochondrial apoptotic pathway.

\section{Introduction}

Osteosarcoma (OS), a cancer more precarious in males, occurs during childhood and adolescence $(1,2)$, with a rate of incidence of 8.7 per million individuals. The cancer usually occurs in a growing long bone (3), such as the humerus (10\%), the distal femur (43\%), or the proximal tibia (23\%). Despite trying to improve results through higher doses, novel therapeutic targets, and new modalities of osteosarcoma therapy, the overall survival rates for osteosarcoma have not significantly improved over the past three decades (4). With the emergence of neoadjuvant chemotherapy prior to surgery, the 5-year survival rate following surgical resection of the osteosarcoma and chemotherapy have improved less than $20 \%$ overall since 1970 , from $65 \%$ to only $70 \%(5,6)$. One key reason could be that osteosarcoma is among the tumors most resistant to all traditional chemotherapeutic agents. Our research was aimed at discovering more efficient agents and reducing the resistance of cancer cells to chemotherapy.

ABT-737 is a BH-3 mimetic that interacts and inhibits Bcl-2, and has been previously shown to be an inducer of cancer cell apoptosis $(7,8)$. This mimetic can inhibit the anti-apoptotic $\mathrm{Bcl}-2$ family of proteins (i.e., $\mathrm{Bcl}-\mathrm{xL}, \mathrm{Bcl}-2$, and $\mathrm{Bcl}-\mathrm{w}$ ), but has a lower effect on Mcl-1 proteins $(9,10)$. Previous research has demonstrated that ABT-737 has a potent single-agent activity or can act synergistically with other chemotherapeutic drugs against various types of hematological malignancies and solid tumors, such as melanoma cells, glioma cells (11), acute myeloid leukemia, chronic lymphocytic leukemia, malignant lymphomas, multiple myelomas, acute lymphoblastic leukemia, and on solid tumors (12). Studies have identified that Bcl-2 expression in human OS cells plays a significant role in Bcl-2-mediated tumor progression (13). Therefore, we assessed the action of ABT-737 for OS treatment. To our knowledge, this is the first study that uses ABT-737 for OS treatment.

In the 1960s and 1970s, cisplatin (cis-diamminedichloroplatinum (II); DDP) was discovered to eliminate and regress tumors on a wide spectrum (14). Neoadjuvant chemotherapy with DDP is one of the first-line anticancer treatments and is used as a general chemotherapy in clinical treatment to 
eliminate or regress possible microscopic metastases $(15,16)$. DDP inhibits the anti-apoptotic Bcl-2 family of proteins Bcl-2 and Mcl-1, whereas ABT-737 inhibits the anti-apoptotic Bcl-2 family of protein Bcl-xL, Bcl-2, and Bcl-w, while having less effect on Mcl-1. Previous research shows that high levels of Mcl-1 confers resistance to ABT-737 (17), thus, we hypothesized that ABT-737 can act synergistically with DDP and tested the action of ABT-737 to enhance the activity of DDP on OS cells. Moreover, DDP has the risk of severe side effects and unpredictable efficacy, so it was imperative to develop less toxic and more effective approaches (18).

Studies from other groups indicate that the mitochondrial apoptotic pathway may be involved in the action of ABT-737 and DDP (19). Apoptosis is composed of two signaling pathways: the extrinsic or death receptor pathway, which is regulated by combining extracellular ligands of the tumor necrosis factor (TNF) family with death receptors, and the intrinsic or mitochondrial pathway, which is controlled by proteins of the B-cell lymphoma (Bcl-2) family (i.e., Bcl-xL, Bcl-w, Mcl-1, Bax, Bak, Bid, Noxa, Puma, and Bim) (9). Interactions and the balance between pro-survival and proapoptotic members could determine the cell's fate (11). When the ratio of Bcl-2 to Bax is reduced, this can cause the severance of the electrochemical gradient across the mitochondrial membranes (20), which influences the mitochondrial outer membrane permeabilization (MOMP), subsequently causing the release of apoptogenic proteins such as cytochrome $c$ into the cytosol. Cytochrome $c$ can bind to Apaf-1 and activate caspase-9, which activates the downstream caspases-3 and/or caspase-7; this triggers a cascade of caspase activations, which in turn results in the cleavage or degradation of several key cellular substrates, including PARP, resulting in cell apoptosis.

In this study, in vitro experiments were conducted to confirm the effects of ABT-737 on human U-2OS cells, alone or in combination with DDP, and the intracellular molecular mechanisms of its actions.

\section{Materials and methods}

Materials. Roswell Park Memorial Institute-1640 (RPMI-1640), fetal bovine serum (FBS), phosphate-buffered saline (PBS), and Hoechst 33258 Staining kit were provided by KeyGEN Biotech (Nanjing, China). CCK-8 was obtained from Solarbio (Beijing, China). Antibodies against Bcl-2, Mcl-1, Bax, cytochrome $c$, caspase-3, caspase-8, caspase-9, and PARP were purchased from Abcam (Cambridge, UK). Antibodies against $\beta$-actin were from Solarbio. Horseradish peroxidase (HRP)-conjugated secondary antibodies were from Transgen (Beijing, China). The Annexin V-PI/FITC Apoptosis Detection Kit was acquired from Becton-Dickinson (San Jose, CA, USA). ABT-737 was obtained from Nanjing ZeLang Medical Technology Co. Ltd. (Nanjing, China). Stock solutions of ABT-737 were prepared by dissolving the ABT-737 powder in DMSO to a concentration of $10 \mathrm{mM}$ and stored at $-80^{\circ} \mathrm{C}$. The working concentrations of ABT-737 were prepared by diluting the stock solution in culture medium. The final concentration of DMSO in the medium was $\leq 0.5 \%$.

Cell culture. The human osteosarcoma cell line U-2OS was obtained from the Type Culture Collection of the Chinese
Academy of Sciences (Shanghai, China), and cultured in RPMI-1640 supplemented with 10\% (v/v) FBS, $100 \mathrm{U} / \mathrm{ml}$ penicillin, and $100 \mu \mathrm{g} / \mathrm{ml}$ streptomycin. Cells were grown in a humidified atmosphere containing $5 \% \mathrm{CO}_{2}$ at $37^{\circ} \mathrm{C}$. The cells used in this study were subjected to less than 20 passages and all cells used in this study were in exponential cell growth.

Cell viability by CCK-8 assay. Cells were cultured in 96-well plates at a concentration of $5 \times 10^{4}$ cells/well. Cell viability was determined by the CCK-8 colorimetric assay. Briefly, the cells were treated with $\operatorname{DDP}(0.75,1.5,3,5,7,9,11$, or $13 \mu \mathrm{g} / \mathrm{ml})$, ABT-737 $(1,2,5,10,20,40$, or $50 \mu \mathrm{M})$, and DDP $(0.75,1.5$, $3,5,7,9,11$, or $13 \mu \mathrm{g} / \mathrm{ml})$ together with ABT-737 $(10 \mu \mathrm{M})$ for 24,48 , or $72 \mathrm{~h}$, whereas the control cells were treated with only $0.5 \%$ DMSO. After the indicated incubation times, $10 \mu \mathrm{l}$ of CCK-8 was added to the plates and they were incubated at $37^{\circ} \mathrm{C}$ for an additional $1-4 \mathrm{~h}$. Following this, the absorbance was measured at $450 \mathrm{~nm}$ using an ELISA plate reader (model EXL800; BioTek Instruments,. Inc., Winooski, VT, USA).

Hoechst 33258 staining of U-2OS cells. Cells were incubated with DDP $(4 \mu \mathrm{g} / \mathrm{ml})$ alone or together with ABT-737 $(10 \mu \mathrm{M})$ for $24 \mathrm{~h}$, harvested, fixed in $4 \%$ paraformaldehyde for $30 \mathrm{~min}$ at $25^{\circ} \mathrm{C}$, washed three times with ice-cold PBS, and stained with $10 \mathrm{mg} / \mathrm{l}$ of Hoechst 33258 (Sigma) in the dark at room temperature $\left(25^{\circ} \mathrm{C}\right)$ for $10 \mathrm{~min}$. Finally, the stained nuclei were observed under a fluorescence microscope (Olympus $\mathrm{x} 100$ ) with the excitation filter at $350 \mathrm{~nm}$ and the emission filter at $460 \mathrm{~nm}$.

Analysis of cell apoptosis by the Annexin V-PI/FITC staining assay. U-2OS cells were stained with Annexin V-PI/FITC (BD Biosciences, San Jose, CA, USA). U-2OS cells were cultured in 24-well plates at a density of $1 \times 10^{5}$ cells/well. Following an overnight incubation, these cells were treated with DDP $(4 \mu \mathrm{g} / \mathrm{ml})$ alone or together with ABT-737 $(10 \mu \mathrm{M})$ for $24 \mathrm{~h}$, whereas the control cells were treated with $0.1 \%$ DMSO. All cells were collected by trypsinization without EDTA. After being washed twice with $4^{\circ} \mathrm{C}$ PBS, cell pellets were suspended in $400 \mu \mathrm{l}$ of ice-cold $1 \mathrm{X}$ binding buffer at a density of nearly $1 \times 10^{6}$ cells $/ \mathrm{ml}$, and then incubated with $5 \mu \mathrm{l}$ of Annexin V-PI/FITC for $15 \mathrm{~min}$ at room temperature $\left(25^{\circ} \mathrm{C}\right)$ in the dark. Samples were analyzed by a flow cytometer within $1 \mathrm{~h}$ after staining.

Western blot analysis. U-2OS cells were cultured in 6-well plates at a density of $2 \times 10^{5}$ cells/well. After treatment with DDP $(4 \mu \mathrm{g} / \mathrm{ml})$ alone or in combination with ABT-737 $(10 \mu \mathrm{M})$ for $24 \mathrm{~h}$, cells were washed with PBS and lysed in cell lysis buffer. Control cells were treated with $0.1 \%$ DMSO and harvested identically. The lysates were centrifuged at $12,000 \times \mathrm{g}$ at $4^{\circ} \mathrm{C}$ for $10 \mathrm{~min}$. The supernatant was collected and the protein concentration was determined by the BCA method. Similar amounts of proteins from each treated cell group were loaded and run on a $10 \%$ SDS-PAGE gel and transferred to polyvinylidene fluoride (PVDF) membranes. The membranes were blocked with $5 \%(\mathrm{w} / \mathrm{v})$ fat-free milk in Tris-buffered saline containing $0.05 \%$ Tween-20 (TBS-T), followed by incubation with a primary antibody overnight at $4^{\circ} \mathrm{C}$. The following day, PVDF membranes were washed in TBS-T three times and 

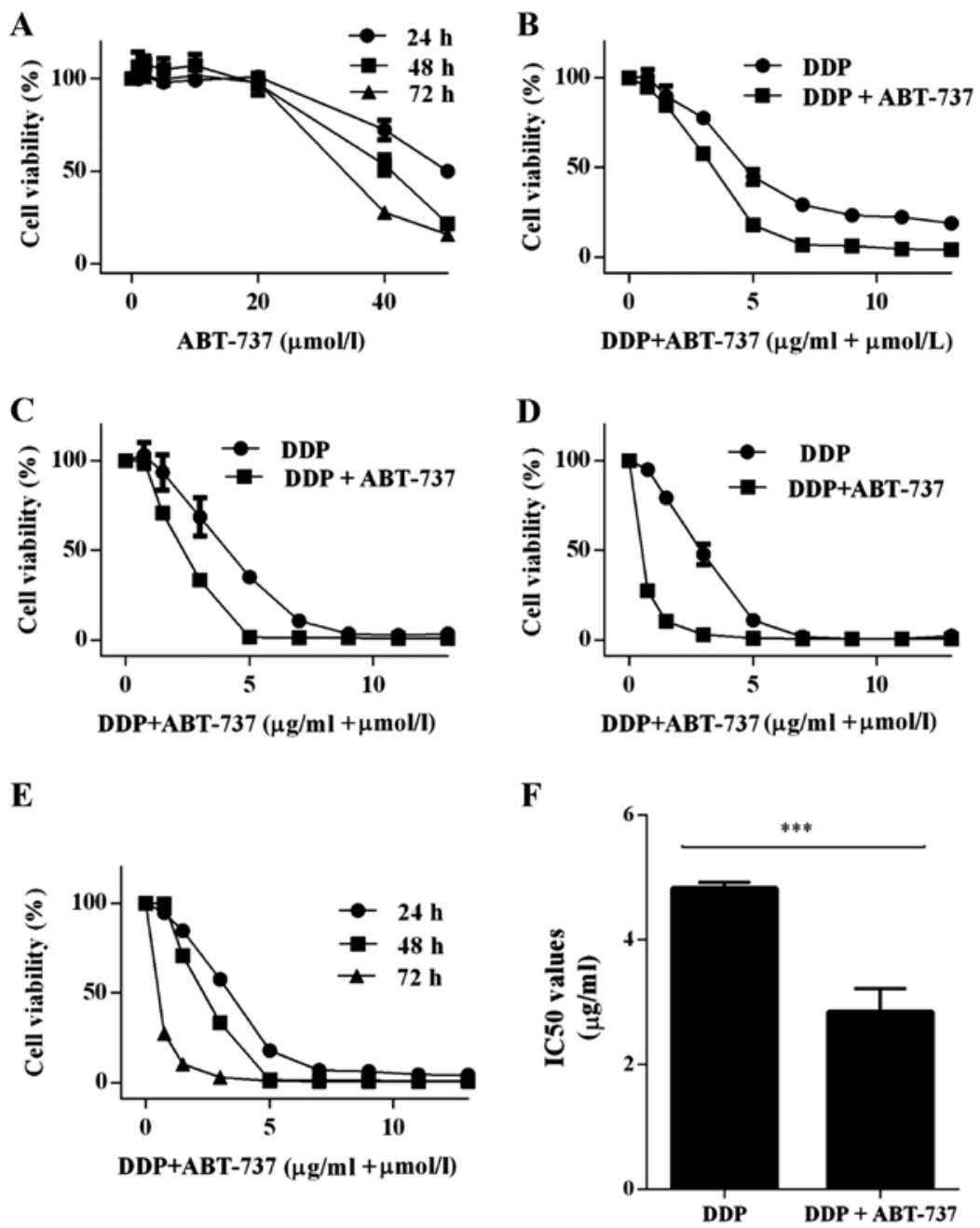

Figure 1. Analysis of cell viability. (A) Effects of ABT-737 treatment on the viability of human U-2OS cells. Cells were treated with ABT-737 at different concentrations and times, as listed in the axes. (B-D) Effects of DDP treatment at different concentrations alone or in combination with ABT-737 (10 $\mu \mathrm{M})$ on the viability of human U-2OS cells for 24,48 , or $72 \mathrm{~h}$. (E) Dose-response and time-course effects of DDP ( $4 \mu \mathrm{g} / \mathrm{ml})$ treated in combination with ABT-737 $(10 \mu \mathrm{M})$ on the viability of human U-2OS cells for 24,36 , or $48 \mathrm{~h}$. Data are presented as means $\pm \mathrm{SD}$ and a representative experiment is shown for the curves. (F) The $\mathrm{IC}_{50}$ values of DDP in U-2OS cells treated with DDP alone and combined with ABT-737 are shown as means $\pm \mathrm{SD} .{ }^{*} \mathrm{P}<0.05,{ }^{* *} \mathrm{P}<0.01,{ }^{* * * *} \mathrm{P}<0.001$.

the membranes were incubated with a horseradish peroxidase (HRP)-conjugated secondary antibody. Immunoreactive proteins were detected by enhanced chemiluminescence (ECL kit; Transgen), followed by exposure to a X-ray film.

Statistics. All data were calculated as means \pm standard deviation (SD) and analyzed by Graphpad Prism 6.0 software. Student's t-test or one-way analysis of variance (ANOVA) were performed to determine the significance of differences between the experimental conditions. All the experiments were repeated at least three times. P-values of $<0.05$ were considered to be statistically significant, $\mathrm{P}<0.05, \mathrm{P}<0.01, \mathrm{P}<0.001$.

\section{Results}

Co-treatment with ABT-737 and DDP reduced the viability of $U-2 O S$ cells. The effects of the treatments on the viability of U-2OS cells were determined by CCK- 8 viability assay, where U-2OS cells were treated with ABT-737 and/or DDP for 24, 48, or $72 \mathrm{~h}$ (Fig. 1A-E). We found that ABT-737 alone only played a very small role in eliminating U-2OS cells at the physiological dose (11) (Fig. 1A). The $\mathrm{IC}_{50}$ value was $50.74 \pm 1.86 \mu \mathrm{M}$ at $24 \mathrm{~h}$. When the cells were treated with DDP and ABT-737 together, there were substantial inhibitory effects on the human U-2OS cells compared to when DDP was used alone in a time- and dose-dependent manner; the $\mathrm{IC}_{50}$ values were $2.84 \pm 0.83 \mu \mathrm{g} / \mathrm{ml}$ (DDP+ABT-737) and $4.82 \pm 0.11 \mu \mathrm{g} / \mathrm{ml}$ (DDP) at $24 \mathrm{~h}$, respectively (Fig. 1E and F).

Since ABT-737 alone had a nominal effect on U-2OS cells, the cells were treated with DDP $(4 \mu \mathrm{g} / \mathrm{ml})$ alone or combined with ABT-737 $(10 \mu \mathrm{M})$ for $24 \mathrm{~h}$ in the following assays.

Induction of morphological changes of U-2OS cells. Untreated $\mathrm{U}-2 \mathrm{OS}$ cells grew well, as seen by phase contrast microscopy. After $24 \mathrm{~h}$ of treatment with DDP alone or in combination with ABT-737, cells appeared more broken, necrosed, and detached when compared to the control cells, which was consistent with the growth inhibition by these treatments. U-2OS cells treated with DDP stained with the fluorescent DNA-binding dye Hoechst 33258 revealed condensed and fragmented nuclei, which is a typical morphological feature of apoptosed cells. In contrast, morphological signs of apoptosis were observed with 
A

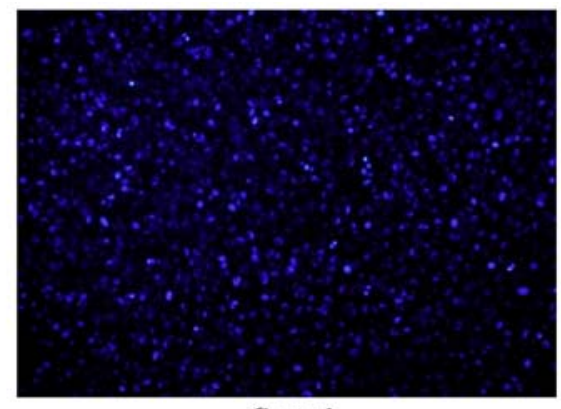

Control

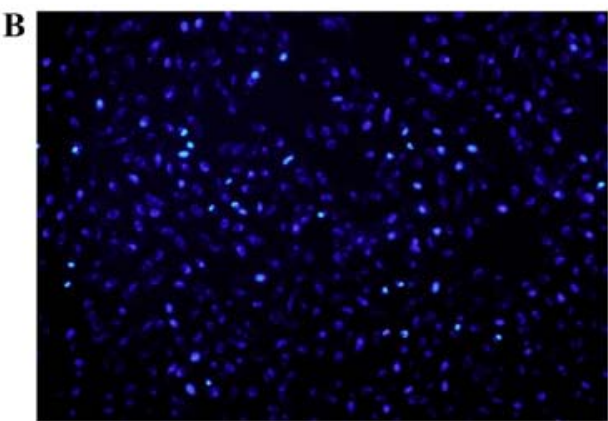

DDP

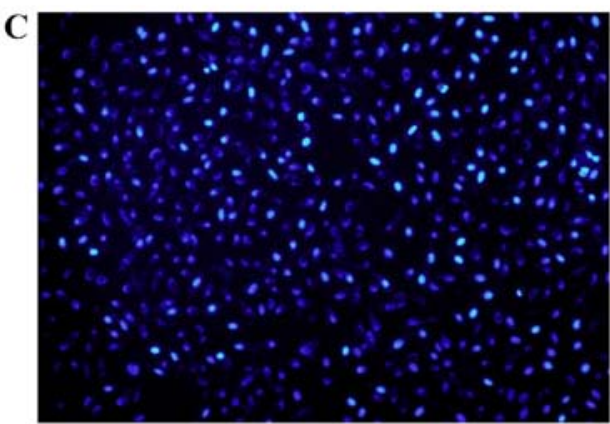

DDP + ABT-737

Figure 2. (A-C) Hoechst 33258 staining of human U-2OS cells. Apoptotic nuclei manifest condensed or fragmented DNA that is brightly stained by Hoechst 33258 (24 h). Magnification, x100.

$\mathbf{A}$

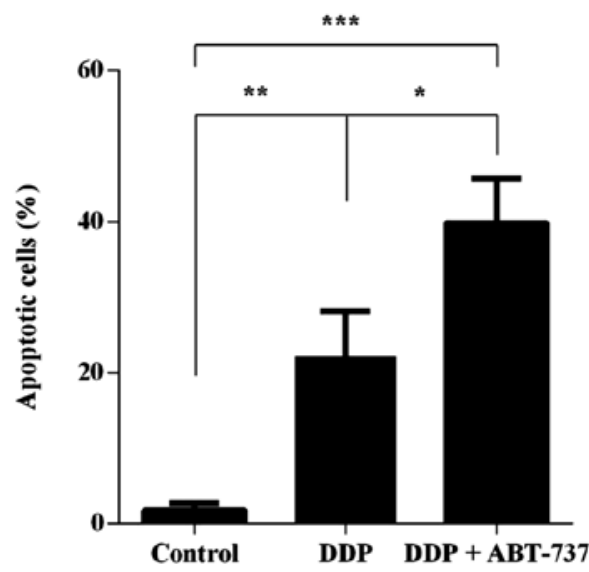

B

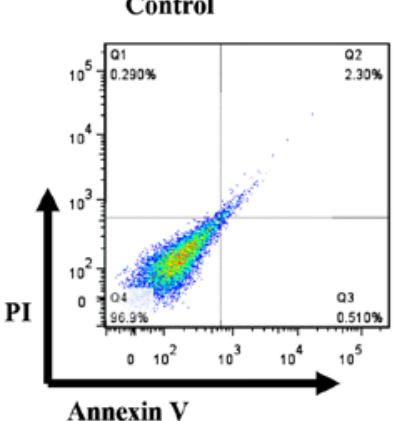

DDP

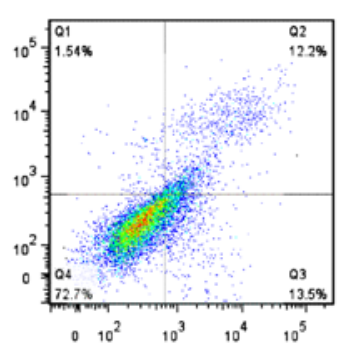

DDP + ABT-737

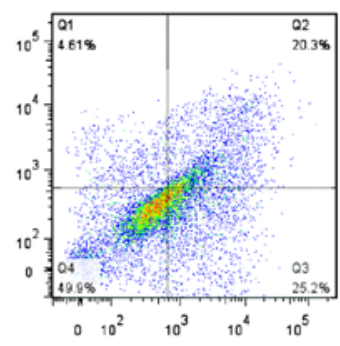

Figure 3. (A) The data shown are the mean $\pm \mathrm{SD}$ (error bars), ${ }^{*} \mathrm{P}<0.05,{ }^{* *} \mathrm{P}<0.01,{ }^{* * *} \mathrm{P}<0.001$. (B) U-2OS cells co-treated with ABT-737 (10 $\left.\mu \mathrm{M}\right)$ and DDP $(4 \mu \mathrm{g} / \mathrm{ml})$ exhibited significantly higher rates of apoptosis $(55.2 \pm 5.61 \%)$ compared to the cells treated with DDP alone $(37.3 \pm 4.67 \%)$.

DDP combined with ABT-737 treatment. The results indicated that DDP alone or together with ABT-737 can induce apoptosis, where the combination therapy had much clearer results (Fig. 2).
Annexin V-PI/FITC staining assay. The rate of cell apoptosis was detected by flow cytometry by double labeling with Annexin V-PI/FITC. The apoptosis rate in control cells was $1.78 \pm 0.96 \%$. The rates of apoptosis were increased to 
A

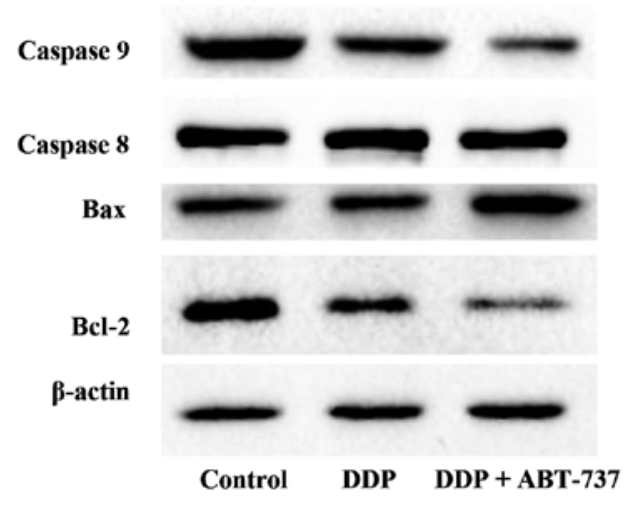

в

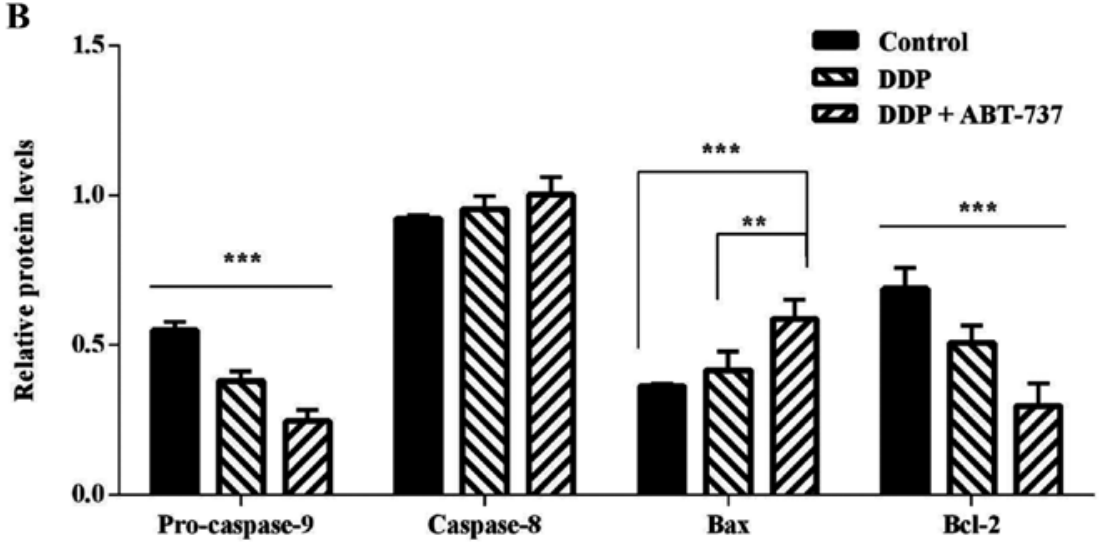

Figure 4. (A) Effect of DDP treatment alone or in combination with ABT-737 treatment on the protein expression levels of caspase-9, caspase-8, Bcl-2 and Bax in human U-2OS cells. $\beta$-actin was used as the internal loading control. (B) Quantification of the western blot analyses. The data shown are the means \pm SD (error bars), ${ }^{*} \mathrm{P}<0.05,{ }^{* * *} \mathrm{P}<0.01,{ }^{* * * *} \mathrm{P}<0.001$.

$22.23 \pm 5.91 \%$ and $39.82 \pm 5.92 \%$ following treatment with DDP alone or in combination with ABT-737 for $24 \mathrm{~h}$, respectively (Fig. 3).

ABT-737 decreases the expression of anti-apoptotic protein Bcl-2, whereas Mcl-1 increases pro-apoptotic proteins Bax and cytochrome $c$. The results of our western blot analyses revealed that DDP treatment combined with ABT-737 caused a marked increase in the expression level of Bax (Fig. 4) proteins and the release of cytochrome $c$ (Fig. 5), whereas it decreased the levels of Bcl-2 and Mcl-1 proteins when compared to the levels in the DDP alone and control treatments, the value of Mcl-1 was $>0.05$ for the DDP alone condition vs. the co-treatment of DDP and ABT-737 (Figs. 4 and 6A). Since DDP could induce U-2OS cell apoptosis via the mitochondrial apoptotic pathway (19), an increase in cytochrome $c$ level was observed, this increase was less than that in the combined treatment group (Fig. 5). This demonstrated that co-treatment with ABT-737 and DDP activated the mitochondrial apoptotic pathway in U-2OS cells via regulating the expression of the Bcl-2 family proteins.

Effects of ABT-737 combined with DDP on the expression levels of caspase proteins. The caspase cascade reaction is one of the most important events in the process of apoptosis through the mitochondrial pathway. Therefore, the protein expression levels of caspase- 9 , caspase- 8 , and caspase- 3 were assessed by western blot analyses. There was no obvious change in caspase- 8 expression, however, the expression levels

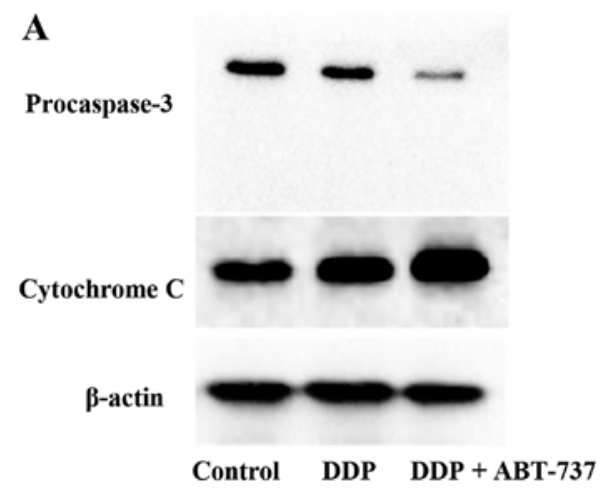

B

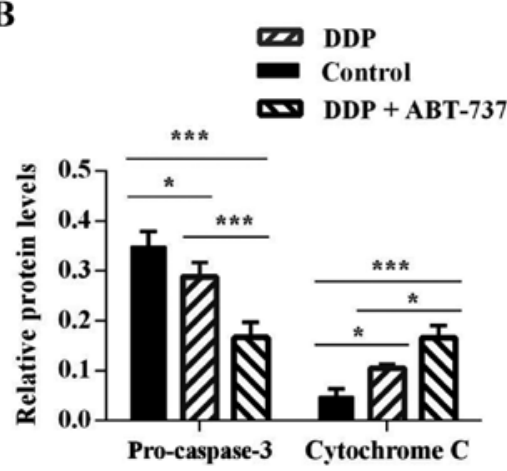

Figure 5. (A) Effect of DDP treatment alone or in combination with ABT-737 treatment on the protein expression levels of caspase-3 and cytochrome $c$ in human U-2OS cells. $\beta$-actin was used as the internal loading control. (B) Quantification of the western blot analyses. The data shown are the means $\pm \mathrm{SD}$ (error bars), ${ }^{*} \mathrm{P}<0.05,{ }^{* *} \mathrm{P}<0.01,{ }^{* * *} \mathrm{P}<0.001$. 

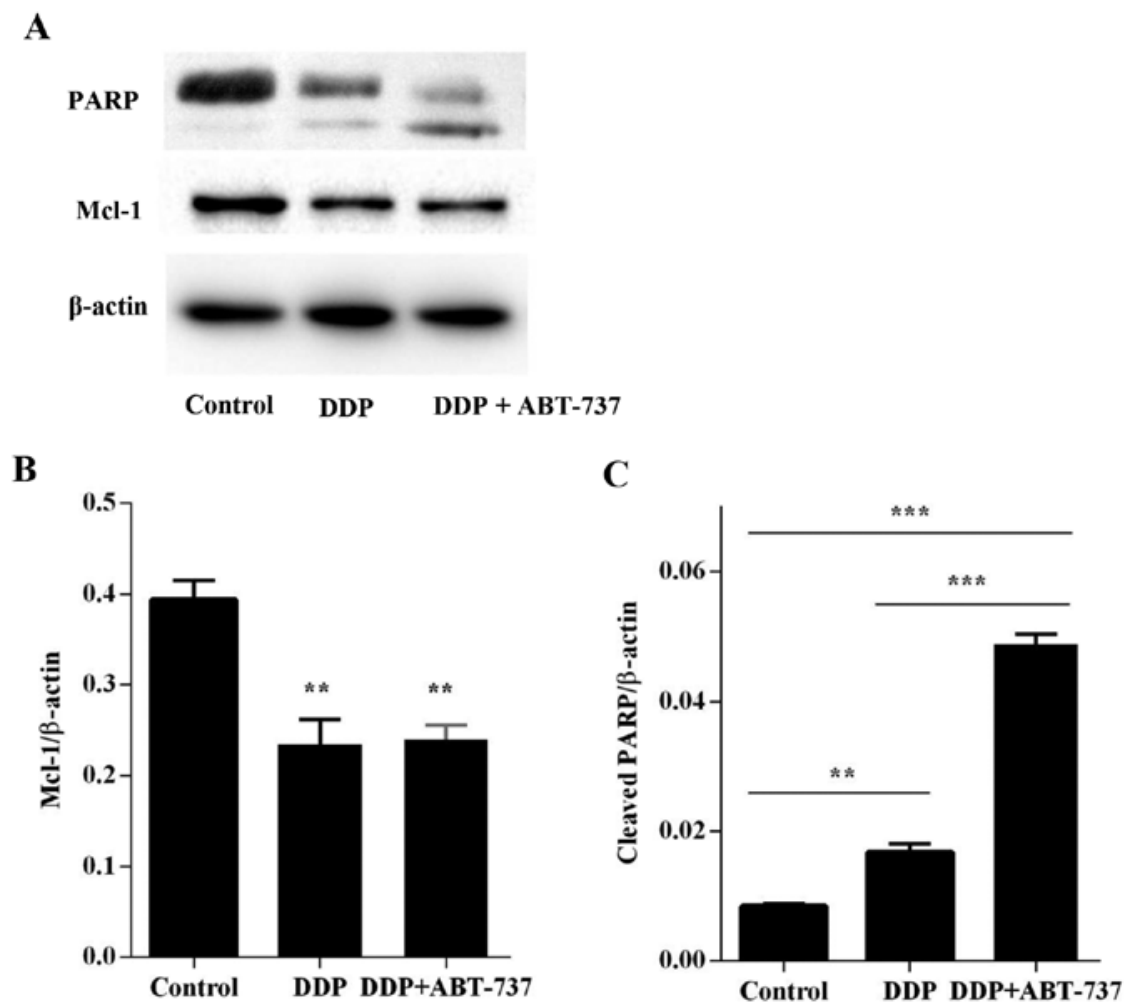

Figure 6. (A) Effect of DDP treatment alone or in combination with ABT-737 treatment on the protein expression levels of Mcl-1 and cleaved PARP in human U-2OS cells. $\beta$-actin was used as the internal loading control. (B-C) Quantification of the western blot analyses. The data shown are the means \pm SD (error bars), ${ }^{*} \mathrm{P}<0.05,{ }^{* *} \mathrm{P}<0.01,{ }^{* * *} \mathrm{P}<0.001$.

of pro-caspase- 9 and pro-caspase-3 were downregulated in the cells treated with DDP alone or combined with ABT-737, where the co-treatment condition showed a more notable decrease in the protein levels. Additionally, the cleavage of PARP, a key cellular substrate, was observed (Figs. 4-6). These results indicated that the apoptosis induced by DDP combined with ABT-737 treatment involved the caspase cascade and was initiated via the mitochondrial pathway.

\section{Discussion}

Apoptosis is an innate cellular response designed to eliminate abnormal or redundant cells (21); therefore, it is considered an important mechanism with which to target cancer cells that evade programmed cell death. There is accumulating evidence that ABT-737 and drugs with antitumor effects can trigger apoptosis in various tumor cells (22). In this study, we determined the anticancer effect and associated mechanisms of ABT-737 in combination with DDP on human U-2OS cells in vitro. CCK-8 viability assay results showed that ABT-737 alone had little influence on U-2OS cells at the clinically administered dose. Previous studies have shown that ABT-737 has the ability to enhance the efficacy of other drugs $(7,19)$ and ABT-737 preferentially inhibits the anti-apoptotic Bcl-2 family proteins Bcl-xL, Bcl-2, and Bcl-w, while having a weaker effect on Mcl-1. Furthermore, previous research shows that high levels of Mcl-1 confer resistance to ABT-737 (17); nevertheless, DDP inhibits the anti-apoptotic Bcl-2 family proteins $\mathrm{Bcl}-2$ and Mcl-1. Therefore, we tried to use DDP and ABT-737 in combination therapy to treat OS. We found ABT-737 treatment combined with DDP effectively suppressed the proliferation of the human U-2OS cell line in a dose- and time-dependent manner. Hoechst 33258 staining and Annexin V-PI/FITC staining analyses further revealed that co-treatment with DDP and ABT-737 can strongly induce apoptosis in OS cells.

Mitochondrial-mediated apoptosis has two signaling pathways for programmed cell death: the death receptor pathway and the mitochondrial pathway, which are regulated via caspase-9 and caspase-8, respectively (23). Previous research has shown that caspases play significant roles in the apoptotic cascade $(24,25)$. In the mitochondrial (intrinsic) pathway, members of the Bcl-2 family can regulate apoptosis downstream of caspase protein activation. An attenuated ratio of $\mathrm{Bcl}-2 / \mathrm{Bax}$ can cause the loss of the electrochemical gradient across the mitochondrial membranes, resulting in apoptosis-associated MOMP that forms pores in the mitochondrial membrane. This leads to the release of many apoptogenic proteins from the mitochondrial intermembranous space, including cytochrome $c$, which can further activate caspase-9. Active caspase- 9 promotes the activity of downstream caspase-3, which causes the cleavage or degradation of key cellular substrates, including PARP, leading to apoptosis (26-33). In the death receptor (extrinsic) pathway, Fas/FasL, which are found on the cell surface, activates the death receptor, which then activates downstream caspase- 8 . Active caspase- 8 can initiate the activity of downstream caspase- 3 , which causes the same cleavage or degradation of key cellular substrates as the intrinsic pathway, leading to apoptosis (34-39).

To deduce the apoptotic signaling mechanism by which DDP combined with ABT-737 acts on OS cells, the expression levels 
of Bcl-2 family proteins, caspase-9, caspase-8, caspase-3, and PARP were tested in U-2OS cells. The present data showed that apoptosis induced by ABT-737 in combination with DDP was accompanied by altering the $\mathrm{Bax} / \mathrm{Bcl}-2$ ratio, and activating caspase- 9 and caspase-3, but not caspase- 8 , The P-value of caspase- 8 was $>0.05$ between each condition (Fig. 4B). On the other hand, the increased cleavage of PARP was discovered when ABT-737 and DDP were used together. Thus, these findings showed that apoptosis induced by ABT-737 in combination with DDP in U-2OS cells was activated by the intrinsic pathway.

Overall, we affirmed that ABT-737 alone had nominal effects on U-2OS cells, whereas in combination with DDP, it upregulated Bax expression and downregulated Bcl-2 expression in human U-2OS cells. This resulted in the release of cytochrome $c$ into cytosol, which further activated caspase-9. Furthermore, caspase- 9 activated downstream caspase-3, which in turn resulted in the cleavage or degradation of several key cellular substrates, including PARP, leading to subsequent cell death. These results indicated that ABT-737 combined with DDP could be a new treatment for OS, while reducing the toxicity of DDP treatment alone.

Further studies are required to elucidate whether ABT-737 can synergize with other chemotherapy drugs, such as doxorubicin and methotrexate. In addition, studies on the in vivo effect of ABT-737 combined with DDP on U-2OS xenograft tumors in nude mice are currently in progress.

\section{Acknowledgements}

This study was supported by The Foundation of Health Department of Jiangxi Province (2016A073) and Gan-Po Talents Project 555 of Jiangxi Province.

\section{References}

1. Delebinski CI, Georgi S, Kleinsimon S, Twardziok M, Kopp B, Melzig MF and Seifert G: Analysis of proliferation and apoptotic induction by 20 steroid glycosides in 143B osteosarcoma cells in vitro. Cell Prolif 48: 600-610, 2015 .

2. Liu SY, Deng SY, He YB and Ni GX: miR-451 inhibits cell growth, migration and angiogenesis in human osteosarcoma via down-regulating IL 6R. Biochem Biophys Res Commun 482: 987-993, 2017.

3. Zhang J, Hou W, Chai M, Zhao H, Jia J, Sun X, Zhao B and Wang R: MicroRNA-127-3p inhibits proliferation and invasion by targeting SETD8 in human osteosarcoma cells. Biochem Biophys Res Commun 469: 1006-1011, 2016.

4. Bishop MW, Janeway KA and Gorlick R: Future directions in the treatment of osteosarcoma. Curr Opin Pediatr 28: 26-33, 2016.

5. Isakoff MS, Bielack SS, Meltzer P and Gorlick R: Osteosarcoma: Current treatment and a collaborative pathway to success. J Clin Oncol 33: 3029-3035, 2015.

6. Gao JZ, Chen FH, Wang L, Wei H and Meng SL: YM155 inhibits tumor growth and enhances chemosensitivity to cisplatin in osteosarcoma. Eur Rev Med Pharmacol Sci 19: 2062-2069, 2015

7. Yu T, Chen C, Sun Y, Sun H, Li TH, Meng J and Shi X: ABT-737 sensitizes curcumin-induced anti-melanoma cell activity through facilitating mPTP death pathway. Biochem Biophys Res Commun 464: 286-291, 2015.

8. Kim LH, Shin JA, Jang B, Yang IH, Won DH, Jeong JH, Chung TH, Cho NP and Cho SD: Sorafenib potentiates ABT-737induced apoptosis in human oral cancer cells. Arch Oral Biol 73: 1-6, 2017.

9. Broecker-Preuss M, Becher-Boveleth N, Müller S and Mann K: The BH3 mimetic drug ABT-737 induces apoptosis and acts synergistically with chemotherapeutic drugs in thyroid carcinoma cells. Cancer Cell Int 16: 27, 2016.
10. Zheng R, You Z, Jia J, Lin S, Han S, Liu A, Long H and Wang S: Curcumin enhances the antitumor effect of ABT-737 via activation of the ROS-ASK1-JNK pathway in hepatocellular carcinoma cells. Mol Med Rep 13: 1570-1576, 2016.

11. Premkumar DR, Jane EP, DiDomenico JD, Vukmer NA, Agostino NR and Pollack IF: ABT-737 synergizes with bortezomib to induce apoptosis, mediated by Bid cleavage, Bax activation, and mitochondrial dysfunction in an Akt-dependent context in malignant human glioma cell lines. J Pharmacol Exp Ther 341: 859-872, 2012.

12. Rao J, Li F, Zhang RY, Zhou HH and Chen GA: BH3 mimetic ABT-737 induces apoptosis in $\mathrm{CD} 4^{+}$acute myeloid leukemia cells and shows synergistic effect with conventional chemotherapeutic drugs. Asia Pac J Clin Oncol 13: e144-e152, 2017.

13. Trieb K, Sulzbacher I and Kubista B: Bcl-2 correlates with localization but not outcome in human osteosarcoma. Oncol Lett 6: 559-561, 2013.

14. Pu F, Chen F, Lin S, Chen S, Zhang Z, Wang B and Shao Z: The synergistic anticancer effect of cisplatin combined with Oldenlandia diffusa in osteosarcoma MG-63 cell line in vitro. Onco Targets Ther 9: 255-263, 2016.

15. Yu L, Fan Z, Fang S, Yang J, Gao T, Simões BM, Eyre R, Guo W and Clarke RB: Cisplatin selects for stem-like cells in osteosarcoma by activating Notch signaling. Oncotarget 7 : 33055-33068, 2016.

16. Han XG, Du L, Qiao H, Tu B, Wang YG, Qin A, Dai KR, Fan QM and Tang TT: CXCR1 knockdown improves the sensitivity of osteosarcoma to cisplatin. Cancer Lett 369: 405-415, 2015.

17. Wu XY, Hao CP, Ling M, Guo CH and Ma W: Hypoxia-induced apoptosis is blocked by adrenomedullin via upregulation of Bcl-2 in human osteosarcoma cells. Oncol Rep 34: 787-794, 2015.

18. Yu X, Zhou X, Fu C, Wang Q, Nie T, Zou F, Guo R, Liu H, Zhang B and Dai M: Celastrol induces apoptosis of human osteosarcoma cells via the mitochondrial apoptotic pathway. Oncol Rep 34: 1129-1136, 2015.

19. Fan Z, Yu H, Cui N, Kong X, Liu X, Chang Y, Wu Y, Sun L and Wang G: ABT737 enhances cholangiocarcinoma sensitivity to cisplatin through regulation of mitochondrial dynamics. Exp Cell Res 335: 68-81, 2015.

20. Péchery A, Fauconnet S, Bittard H and Lascombe I: Apoptotic effect of the selective PPAR $\beta / \delta$ agonist GW501516 in invasive bladder cancer cells. Tumour Biol 37: 14789-14802, 2016.

21. Li J, Yang Z, Li Y, Xia J, Li D, Li H, Ren M, Liao Y, Yu S, Chen Y, et al: Cell apoptosis, autophagy and necroptosis in osteosarcoma treatment. Oncotarget 7: 44763-44778, 2016.

22. Shen J, Xu L and Zhao Q: Perifosine and ABT-737 synergistically inhibit lung cancer cells in vitro and in vivo. Biochem Biophys Res Commun 473: 1170-1176, 2016.

23. Xu G, Kuang G, Jiang W, Jiang $R$ and Jiang D: Polydatin promotes apoptosis through upregulation the ratio of $\mathrm{Bax} / \mathrm{Bcl}-2$ and inhibits proliferation by attenuating the $\beta$-catenin signaling in human osteosarcoma cells. Am J Transl Res 8: 922-931, 2016.

24. Xiong M, Wang L, Yu HL, Han H, Mao D, Chen J, Zeng Y, He N, Liu ZG, Wang ZY, et al: Ginkgetin exerts growth inhibitory and apoptotic effects on osteosarcoma cells through inhibition of STAT3 and activation of caspase-3/9. Oncol Rep 35: 1034-1040, 2016.

25. Li YL, Sun J, Hu X, Pan YN, Yan W, Li QY, Wang F, Lin NM and Zhang C: Epothilone B induces apoptosis and enhances apoptotic effects of ABT-737 on human cancer cells via PI3K/AKT/mTOR pathway. J Cancer Res Clin Oncol 142: 2281-2289, 2016.

26. Niu NK, Wang ZL, Pan ST, Ding HQ, Au GH, He ZX, Zhou ZW, Xiao G, Yang YX, Zhang X, et al: Pro-apoptotic and proautophagic effects of the Aurora kinase A inhibitor alisertib (MLN8237) on human osteosarcoma U-2 OS and MG-63 cells through the activation of mitochondria-mediated pathway and inhibition of $\mathrm{p} 38 \mathrm{MAPK} / \mathrm{PI} 3 \mathrm{~K} / \mathrm{Akt} / \mathrm{mTOR}$ signaling pathway. Drug Des Devel Ther 9: 1555-1584, 2015.

27. Lin $\mathrm{CH}$, Hong YC and Kao SH: Aeroallergen Der p 2 induces apoptosis of bronchial epithelial BEAS-2B cells via activation of both intrinsic and extrinsic pathway. Cell Biosci 5: 71, 2015.

28. Zhe N, Chen S, Zhou Z, Liu P, Lin X, Yu M, Cheng B, Zhang Y and Wang J: HIF-1 $\alpha$ inhibition by 2 -methoxyestradiol induces cell death via activation of the mitochondrial apoptotic pathway in acute myeloid leukemia. Cancer Biol Ther 17: 625-634, 2016.

29. Lee YJ, Kim SA and Lee SH: Hyaluronan suppresses lidocaineinduced apoptosis of human chondrocytes in vitro by inhibiting the p53-dependent mitochondrial apoptotic pathway. Acta Pharmacol Sin 37: 664-673, 2016. 
30. Jiang X, Li L, Ying Z, Pan C, Huang S, Li L, Dai M, Yan B, Li M, Jiang H, et al: A small molecule that protects the integrity of the electron transfer chain blocks the mitochondrial apoptotic pathway. Mol Cell 63: 229-239, 2016.

31. Zhai X, Ding Y, Wang Q, Zhang H and Li F: Rutin acid ameliorates neural apoptosis induced by traumatic brain injury via mitochondrial pathways in mice. Neuroimmunomodulation 23: 179-187, 2016

32. Tian X, Shi Y, Liu N, Yan Y, Li T, Hua P and Liu B: Upregulation of DAPK contributes to homocysteine-induced endothelial apoptosis via the modulation of $\mathrm{Bcl} 2 / \mathrm{Bax}$ and activation of caspase 3. Mol Med Rep 14: 4173-4179, 2016.

33. Wu Y, Shamoto-Nagai M, Maruyama W, Osawa T and Naoi M: Phytochemicals prevent mitochondrial membrane permeabilization and protect SH-SY5Y cells against apoptosis induced by PK11195, a ligand for outer membrane translocator protein. J Neural Transm (Vienna) 124: 89-98, 2017.

34. Zhang F, Chen L, Jin H, Shao J, Wu L, Lu Y and Zheng S: Activation of Fas death receptor pathway and Bid in hepatocytes is involved in saikosaponin D induction of hepatotoxicity. Environ Toxicol Pharmacol 41: 8-13, 2016.

35. Horie Y, Nemoto H, Itoh M, Kosaka H and Morita K: Fermented brown rice extract causes apoptotic death of human acute lymphoblastic leukemia cells via death receptor pathway. Appl Biochem Biotechnol 178: 1599-1611, 2016.
36. Kwon SB, Kim MJ, Yang JM, Lee HP, Hong JT, Jeong HS, Kim ES and Yoon DY: Cudrania tricuspidata stem extract induces apoptosis via the extrinsic pathway in SiHa cervical cancer cells. PLoS One 11: e0150235, 2016.

37. Han MH, Lee WS, Nagappan A, Kim HJ, Park C, Kim GY, Hong SH, Kim ND, Kim G, Ryu CH, et al: Polyphenols from Korean prostrate spurge Euphorbia supina induce apoptosis through the Fas-associated extrinsic pathway and activation of ERK in human leukemic U937 cells. Oncol Rep 36: 99-107, 2016.

38. Chen H, Tang X, Zhou B, Xu N and Wang Y: Mechanism of DecaBDE-induced apoptosis in Neuro-2a cells: Role of death-receptor pathway and reactive oxygen species-mediated mitochondrial pathway. J Environ Sci (China) 46: 241-251, 2016.

39. Liang S, Sun K, Wang Y, Dong S, Wang C, Liu L and Wu Y: Role of Cyt-C/caspases-9,3, Bax/Bcl-2 and the FAS death receptor pathway in apoptosis induced by zinc oxide nanoparticles in human aortic endothelial cells and the protective effect by alphalipoic acid. Chem Biol Interact 258: 40-51, 2016. 